\title{
The performance of a 3-Phase Induction Machine under Unbalance Voltage Regime
}

\author{
Adekitan Aderibigbe $^{1, *}$, Ayodeji Ogunjuyigbe ${ }^{2}$, Raphael Ayodele ${ }^{2}$ and Isaac Samuel ${ }^{1}$ \\ ${ }^{1}$ Department of Electrical and Information Engineering, Covenant University, Ota, Ogun State, Nigeria \\ ${ }^{2}$ Department of Electrical and Electronic Engineering, University of Ibadan, Ibadan, Oyo State, Nigeria
}

Received 10 September 2017; Accepted 7 November 2017

\begin{abstract}
In industries, electric motors contribute a major percentage of electrical loads, and by implication, a major portion of the generated electrical energy is consumed by electric motors, and it is therefore vital to ensure that these motors operate with negligible energy loss. In operational environment, many factors can be responsible for a reduction in motor performance. One of the major factors is a regime of voltage unbalance that affects the motor, the load and supply network. Three phase induction motor studies can be carried out using methods such as real load test, finite element analysis, flux linkage-current relations etc. A new model based on phase frame analysis has been developed for easy computation of sequence components. This paper seeks to explore the performance of a 3-phase induction motor operating under unbalance voltage conditions using the phase frame analysis. The results of this study established that there are negative impacts of supply imbalance on the performance of three phase motor.
\end{abstract}

Keywords: Voltage unbalance, Motor performance characteristics, three phase induction motor, negative sequence component, phase frame analysis, industrial machines

\section{Introduction}

Poly-phase supply system is the major form of alternating current supply network today. In theory, each supply phase voltage is designed to be at the same magnitude, but this ideal condition is rarely so in practical systems. Voltage imbalance is a common problem in poly-phase system. For three phase supply system, when there is a minor variation among the phase voltages of a poly phase system, the effect is often negligible and most motors are designed to tolerate this expected minor voltage variations except in very sensitive electrical systems. According to [1] the newer models of induction motors are comparatively more sensitive to unbalance voltage than the previous models, and for adjustable speed drives the susceptibility is further increased. The performance of an induction motor can be compromised when there is an excessive voltage variation, and the resultant undesired effects need to be studied, understood and mitigated. Motor-driven systems use more than $66 \%$ of the total electrical energy consumption of industries [2], and this makes electric motor a major support for industrial operations. To guarantee that energy is efficiently utilized by these motors, it is vital to ensure that all form of losses are identified and at least reduced if not completely eliminated. It has been established that there are energy losses associated with voltage unbalance and this calls for continuous and extensive research studies on the performance of induction motors operating under voltage unbalance conditions.

The sequence component analysis of induction motors requires an intricate calculation that entails successive motor parameter transformation from phase to sequence and back to phase form. This can be daunting and error prone if not

*E-mail address: ade_kitan@yahoo.com

ISSN: $1791-2377$ @ 2017 Eastern Macedonia and Thrace Institute of Technology. All rights reserved. doi:10.25103/iestr.105.17 properly handled. A new analytical approach termed Phase Frame Analysis was developed by [3] which progressively transformed symmetrical motor equivalent model into a new phase frame analytical model. This research work further explores the phase frame motor model, by applying same for an extensive motor performance studies under voltage unbalance conditions. This paper does not assume a constant average voltage during unbalance conditions which was assumed by [3]; the average voltage varied in accordance with the supply line voltages which is a reflection of practical operational situation.

In this study, motor performance parameters such as winding copper losses, motor efficiency, output power per phase, magnetizing current, sequence torque, power factor and phase power variation were all studied under a regime of voltage magnitude unbalance.

\section{Voltage Unbalance}

A symmetrical three phase supply system has three identical phases with the voltage of each phase and line equal in magnitude and displaced from each other by $120^{\circ}$, but as a result of a number of possible factors, the terminal voltage at the load end is often unbalanced. According to [4], "in a 3phase supply system, voltage unbalance condition is when the phase or line voltage magnitudes are not the same, and the phase angles of each phase varies from the balanced voltage conditions, or both." Experiences in the electrical field as revealed that unequal sharing of single phase loads among the three supply phases, which may also frequently vary is one of the major causes of unbalance [5].

Machines are designed to operate at balanced rated voltage level, and according to [6] "all induction motors have some inherent phase unbalance due primarily to mass production tolerances" such that these four conditions often play out during motor operation, these are 
a) Rated Voltage Operation

b) Balanced Over-voltage Supply Condition

c) Balanced Under-voltage Supply Condition

d) Unbalance Voltage Supply Condition

\subsection{Fundamental factors that result in Voltage Unbalance}

The following are three of some of the major causes of voltage unbalance:

\section{a) The source of supply}

The configuration and components of a supply network greatly influences the voltage stability of the supply, and the effect is further amplified when there are defective system components like transformer faults, unequal power supply line impedances, blown fuses, unequal sharing of single phase loads among the three phases etc. and as opined by [7], the number of single phase loads compared to three phase load also determines voltage stability.

\section{b) The motor}

Induction motors windings has both resistive and inductive impedances and when there is an imbalance between this components among the three phases, it can result in the flow of imbalance current of greater magnitude than the magnitude of voltage imbalance. [1] Further asserts that circuit connection faults, partial contacts, defects in the windings of the rotor and stator can result in uneven impedances among the three phases of the motor and this ultimately leads to voltage unbalance.

\section{c) Load Type}

Generally, loads have deferent load current profile, and the type of load used within and around a facility can result in line voltage unbalance; such as the use of heavy duty reactive loads like welding machines. The supply system voltage stability is greatly affected by the nature of the current drawn by these loads.

\subsection{Definitions of Voltage Unbalance}

There are different definitions of voltage unbalance and [4] asserts that there is a need to understand the implications for using any of the definitions, as there are slight variations between the percentage unbalance obtained using three different methods for the same set of voltage. This difference becomes significant for high level of unbalance when the NEMA definition is used.

According to the works of [4, 8-10], voltage unbalance can be defined as follows:

\section{a) NEMA}

National Electrical Manufactures Association Motor and Generator Standard (NEMA MG1.1993) defines it, in terms of the Line Voltage Unbalance in Percentage (LVUP) at the terminal of a machine

\section{LVUP $=$}

$\underline{\text { (max imum voltage deviation from average line voltage) }} \times 100 \%$

$=\frac{\operatorname{Max}\left[\left|\mathrm{V}_{\mathrm{ab}}-\mathrm{V}_{\text {Lavg }}\right|,\left|\mathrm{V}_{\mathrm{bc}}-\mathrm{V}_{\text {Lavg }}\right|,\left|\mathrm{V}_{\mathrm{ca}}-\mathrm{V}_{\text {Lavg }}\right|\right]}{\mathrm{V}_{\text {Lavg }}} \times 100 \%$

Where $\mathrm{V}_{\text {Lavg }}=\frac{\left(\mathrm{V}_{\mathrm{ab}}+\mathrm{V}_{\mathrm{bc}}+\mathrm{V}_{\mathrm{ca}}\right)}{3}$

b) IEEE

IEEE Std 141, defines it in terms of the Phase Voltage Unbalance in Percentage (PVUP) at the terminal of a machine. The phase voltage unbalance in percentage PVUP is defined as

$$
\text { PVUR }=\frac{\operatorname{Max}\left[\left|\mathrm{V}_{\mathrm{a}}-\mathrm{V}_{\text {Pavg }}\right|,\left|\mathrm{V}_{\mathrm{b}}-\mathrm{V}_{\text {Pavg }}\right|,\left|\mathrm{V}_{\mathrm{c}}-\mathrm{V}_{\text {Pavg }}\right|\right]}{\mathrm{V}_{\text {Pavg }}} \times 100 \%
$$

Where $\mathrm{V}_{\text {Pavg }}=\frac{\left(\mathrm{V}_{\mathrm{a}}+\mathrm{V}_{\mathrm{b}}+\mathrm{V}_{\mathrm{c}}\right)}{3}$

c) Negative Sequence Voltage Unbalanced Factor

This is the accepted definition of voltage unbalance by IEC 60034-26 and it is called IEC definition or the Voltage Unbalance Factor (VUF) [11]. VUF is defined as the ratio of the sequence voltage components, the negative sequence voltage and the positive sequence:

$$
\begin{aligned}
& \text { VUF }(\%)=\frac{\text { Negative sequence voltage component magnitude }}{\text { Positive vequence voltage component magnitude }} \times 100 \% \\
& \text { VUF }(\%)=\frac{V_{2}}{V_{1}} \times 100 \%
\end{aligned}
$$

Where VI and V2 are obtained by resolving the unbalance voltage into its symmetrical component

$$
\mathrm{V}_{1}=\frac{\mathrm{V}_{\mathrm{ab}}+\mathrm{aV}_{\mathrm{bc}}+\mathrm{a}^{2} \mathrm{~V}_{\mathrm{ca}}}{3}
$$

$\mathrm{V}_{2}=\frac{\mathrm{V}_{\mathrm{ab}}+\mathrm{a}^{2} \mathrm{~V}_{\mathrm{bc}}+\mathrm{aV}_{\mathrm{ca}}}{3}$

According to [12], common attendant consequences of unbalance voltage includes:
a) Decline in motor efficiency
b) Early motor failure due to excess heat
c) De-rating of poly-phase induction motors

For the energy consumers, a decrease in efficiency and increase in reactive power translates to increase in energy consumption and the associated cost. This also creates additional load on the power supply network, and ultimately leads to a reduction in the power plant's power reserve [13].

\section{Phase Frame Analysis of three phase induction motor characteristics}

Analysis of the operations of an induction motor is traditionally carried using symmetrical component method, using the positive and negative sequence equivalent circuits of an induction motor. A method was developed by [3] for carrying out all analysis in the phase frame directly, thereby eliminating the need to transform the results from the sequence component to the phase form. This saves computation effort and time, and it gives a direct answer in the phase voltage frame.

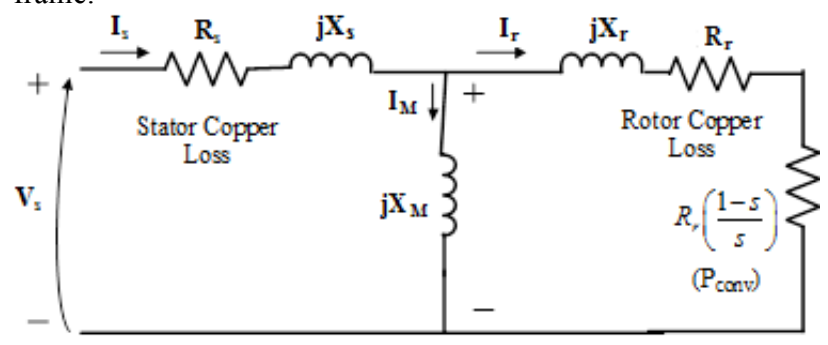

Fig 1. Sequence equivalent circuit of an induction motor 
The equivalent impedance $\mathrm{Zmi}$ of the circuit is given by

$\mathrm{ZM}_{\mathrm{i}}=\mathrm{R}_{\mathrm{si}}+\mathrm{jX} \mathrm{Si}_{\mathrm{si}}+\frac{\mathrm{JX}_{\mathrm{mi}} x\left(\mathrm{R}_{\mathrm{ri}}+\mathrm{RL}_{\mathrm{i}}+\mathrm{j} \mathrm{X}_{\mathrm{ri}}\right)}{\mathrm{R}_{\mathrm{ri}}+\mathrm{RL}_{\mathrm{i}}+\mathrm{j}\left(\mathrm{X}_{\mathrm{mi}}+\mathrm{X}_{\mathrm{ri}}\right)}$

The Load resistance $R L_{i}=\frac{1-s_{i}}{s_{i}} \times R_{r i}$

Positive sequence slip $s_{1}=\frac{n_{s}-n}{n_{s}}$

Negative sequence slips $s_{2}=2-s$

The terms are defined as follows

Let $\mathrm{i}=1$ or 2 , for positive sequence and negative sequence Vs is the applied motor terminal voltage

Is is the stator current

$\mathrm{Rs}$ and $\mathrm{Xs}$ are the stator effective resistance and reactance respectively.

Ir is the rotor current

$\mathrm{Rr}$ and $\mathrm{Xr}$ are the referred rotor effective resistance and reactance respectively

Xm Magnetizing inductance

The line to line voltage is transformed to sequence line to line voltage using

$$
[\mathrm{VLL}]_{\mathrm{seq}}=\left[\begin{array}{c}
\mathrm{V}_{\mathrm{ab} 0} \\
\mathrm{~V}_{\mathrm{ab} 1} \\
\mathrm{~V}_{\mathrm{ab} 2}
\end{array}\right]=[\mathrm{A}]^{-1} \cdot[\mathrm{VLL}]_{\mathrm{abc}}
$$

Where $\mathrm{A}$ is the symmetrical components transformation matrix

$$
\mathrm{t}=\frac{1}{\sqrt{3}} \angle-30
$$

The sequence line to neutral voltage can be defined as

$$
[\mathrm{VLN}]_{\mathrm{seq}}=\left(\begin{array}{c}
\mathrm{V}_{\mathrm{an} 0} \\
\mathrm{~V}_{\mathrm{an} 1} \\
\mathrm{~V}_{\mathrm{an} 2}
\end{array}\right)=\left(\begin{array}{ccc}
1 & 0 & 0 \\
0 & t & 0 \\
0 & 0 & t^{*}
\end{array}\right)\left(\begin{array}{c}
\mathrm{V}_{\mathrm{ab} 0} \\
\mathrm{~V}_{\mathrm{ab} 1} \\
\mathrm{~V}_{\mathrm{ab} 2}
\end{array}\right)
$$

$=[\mathrm{T}] \cdot[\mathrm{VLL}]_{\mathrm{seq}}$

Let Admittance $\mathrm{YM}_{\mathrm{i}}=\frac{1}{\mathrm{ZM}_{\mathrm{i}}}$

The sequence currents are

$$
\begin{aligned}
& \left(\begin{array}{c}
I_{\mathrm{a} 0} \\
I_{\mathrm{a} 1} \\
I_{\mathrm{a} 2}
\end{array}\right)=\left(\begin{array}{ccc}
1 & 0 & 0 \\
0 & t \cdot \mathrm{YM}_{1} & 0 \\
0 & 0 & t^{*} \cdot \mathrm{YM}_{2}
\end{array}\right)\left(\begin{array}{c}
\mathrm{V}_{\mathrm{ab} 0} \\
\mathrm{~V}_{\mathrm{ab} 1} \\
\mathrm{~V}_{\mathrm{ab} 2}
\end{array}\right) \\
& {\left[\mathrm{I}_{\mathrm{abc}}=[\mathrm{A}] \cdot[\mathrm{I}]_{\mathrm{seq}}\right.} \\
& \mathrm{Y}_{\mathrm{m}}=\frac{1}{\mathrm{jX}}
\end{aligned}
$$

The sequence stator impedance $\mathrm{Z}_{\mathrm{si}}=\mathrm{R}_{\mathrm{si}}+\mathrm{j} \mathrm{X}_{\mathrm{si}}$

The sequence rotor impedance $Z_{r i}=R_{r i}+j X_{r i}$
The ABCD parameters of the unsymmetrical $\mathrm{T}$ circuit obtained by removing the load resistor from figure 1 is defined below

$$
\begin{aligned}
& \mathrm{A}_{\mathrm{mi}}=1+\mathrm{Y}_{\mathrm{mi}} \cdot \mathrm{Z}_{\mathrm{si}} \\
& \mathrm{B}_{\mathrm{mi}}=\mathrm{Z}_{\mathrm{si}}+\mathrm{Z}_{\mathrm{ri}}+\mathrm{Y}_{\mathrm{mi}} \cdot \mathrm{Z}_{\mathrm{si}} \cdot \mathrm{Z}_{\mathrm{ri}} \\
& \mathrm{C}_{\mathrm{mi}}=\mathrm{Y}_{\mathrm{mi}}
\end{aligned}
$$

$\mathrm{D}_{\mathrm{mi}}=1+\mathrm{Y}_{\mathrm{mi}} \cdot \mathrm{Z}_{\mathrm{ri}}$

$$
\left(\begin{array}{c}
V_{r 0} \\
V_{r 1} \\
V_{r 2} \\
I_{r 0} \\
I_{r 1} \\
I_{r 2}
\end{array}\right)=\left(\begin{array}{cccccc}
0 & 0 & 0 & 0 & 0 & 0 \\
0 & D_{m 1} & 0 & 0 & -B_{m 1} & 0 \\
0 & 0 & D_{m 2} & 0 & 0 & -B_{m 2} \\
0 & 0 & 0 & 0 & 0 & 0 \\
0 & -C_{m 1} & 0 & 0 & A_{m 1} & 0 \\
0 & 0 & -C_{m 2} & 0 & 0 & A_{m 2}
\end{array}\right)\left(\begin{array}{c}
V_{s 0} \\
V_{s 1} \\
V_{s 2} \\
I_{s 0} \\
I_{s 1} \\
I_{s 2}
\end{array}\right)
$$

The extent and effect of voltage unbalance can be determined by monitoring key motor performance parameters; both electrical and mechanical.

From figure 1, the magnetizing current is defined as

$$
I_{m}=I_{s i} \times \frac{R_{r i}+R L_{i}+j X_{r i}}{R_{r i}+R L_{i}+j\left(X_{m i}+X_{r i}\right)}
$$

The total input power into the motor is given by

$$
\mathrm{P}_{\mathrm{in}}=\operatorname{Real}\left[\mathrm{Vs}_{\mathrm{sa}} \cdot \mathrm{Is}_{\mathrm{a}}{ }^{*}+\mathrm{Vs}_{\mathrm{sb}} \cdot \mathrm{Is}_{\mathrm{b}}{ }^{*}+\mathrm{Vs}_{\mathrm{sc}} \cdot \mathrm{Is}_{\mathrm{c}}{ }^{*}\right]
$$

The resistive copper loss in the stator and rotor can be obtained from

$\mathrm{P}_{\mathrm{s}}=\left|\mathrm{Is}_{\mathrm{a}}\right|^{2} \cdot \mathrm{R}_{\mathrm{sa}}+\left|\mathrm{Is}_{\mathrm{b}}\right|^{2} \cdot \mathrm{R}_{\mathrm{sb}}+\left|\mathrm{Is}_{\mathrm{c}}\right|^{2} \cdot \mathrm{R}_{\mathrm{sc}}$

$\mathrm{P}_{\mathrm{r}}=\left|\mathrm{Ir}_{\mathrm{a}}\right|^{2} \cdot \mathrm{R}_{\mathrm{ra}}+\left|\mathrm{Ir}_{\mathrm{b}}\right|^{2} \cdot \mathrm{R}_{\mathrm{rb}}+\left|\mathrm{Ir}_{\mathrm{c}}\right|^{2} \cdot \mathrm{R}_{\mathrm{rc}}$

$\mathrm{P}_{\mathrm{EM}}=\operatorname{Real}\left[\mathrm{Vr}_{\mathrm{a}} \cdot \mathrm{Ir}_{\mathrm{a}}^{*}+\mathrm{Vr}_{\mathrm{b}} \cdot \mathrm{Ir}_{\mathrm{b}}^{*}+\mathrm{Vr}_{\mathrm{c}} \cdot \mathrm{Ir}_{\mathrm{c}}^{*}\right]$

For the motor output torque, as analyzed by [14]

Let $\mathrm{T}_{\mathrm{M}}$ be the motor torque developed

Let $\mathrm{T}_{\mathrm{L}}$ be the load torque

For the motor to operate at steady state $T_{M}=T_{L}$

But under unbalance voltage scenario $T_{M}=T_{P}+T_{N}$

Where TP is the positive component of the sequence torque $\mathrm{Tn}$ is the negative component of the sequence torque

$$
\begin{aligned}
& T_{\mathrm{p}}=3 \mathrm{I}_{\mathrm{r} 1}{ }^{2} \frac{\mathrm{R}_{\mathrm{r}}}{\mathrm{sW}_{\mathrm{s}}} \\
& T_{\mathrm{n}}=3 \mathrm{I}_{\mathrm{r} 2}{ }^{2} \frac{\mathrm{R}_{\mathrm{r}}}{(2-\mathrm{s}) \mathrm{W}_{\mathrm{s}}}
\end{aligned}
$$

The motor net output torque

$$
T=T_{p}+T_{n}=\frac{3 R_{r}}{W_{s}}\left[\frac{I_{r 1}^{2}}{s}-\frac{I_{r 2}^{2}}{2-s}\right]
$$




\section{Adekitan Aderibigbe, Ayodeji Ogunjuyigbe, Raphael Ayodele and Isaac Samuel/}

\section{Journal of Engineering Science and Technology Review 10 (5) (2017) 136-143}

Using sequence components we can also define real and reactive input power as follows

$\mathrm{P}_{\mathrm{in}}=\operatorname{Real}\left[3 \times\left(\mathrm{V}_{\mathrm{s} 1} \cdot \mathrm{I}_{\mathrm{s} 1}{ }^{*}+\mathrm{V}_{\mathrm{s} 2} \cdot \mathrm{I}_{\mathrm{s} 2}{ }^{*}\right)\right]$

$\mathrm{Q}_{\mathrm{in}}=\operatorname{Imag}\left[3 \times\left(\mathrm{V}_{\mathrm{s} 1} \cdot \mathrm{I}_{\mathrm{s} 1}{ }^{*}+\mathrm{V}_{\mathrm{s} 2} \cdot \mathrm{I}_{\mathrm{s} 2}{ }^{*}\right)\right]$

Input power factor $\mathrm{P}_{\mathrm{f}}=\operatorname{Cos}\left(\tan ^{-1}\left[\frac{\mathrm{Q}_{\mathrm{in}}}{\mathrm{P}_{\mathrm{in}}}\right]\right)$

\section{Simulations and analysis}

A Matlab simulation was developed based on the phase frame analysis, to analyse the effect of unbalanced voltage on the performance characteristics of a three phase induction machine. In this model, the motor circuit components are assumed constant.

In the Simulation, the performance characteristics of a three phase induction motor working under voltage unbalance with average voltage variations above and below the motor rated voltage was studied. During voltage unbalance conditions, the manner in which the variation will occur and the extent of the voltage variation cannot be pre-determined. Therefore the prevailing supply voltage deviates randomly from the nominal average supply voltage during unbalance conditions.

The effect of the unbalance on the electrical and mechanical motor performance parameter is duly considered. The voltage unbalance was allowed to vary between $0-10 \%$, so as to observe the impact of the unbalance above the NEMA recommended $0-5 \%$ range.

To achieve this, a study was carried out using the following parameters of a $25 \mathrm{~kW}$ three phase induction motor:

$\mathrm{V}=415 \mathrm{~V}$

$\mathrm{Rs}=0.1134 \Omega$

$\mathrm{Rr}=0.1907 \Omega$

$\mathrm{Xs}=0.2268 \Omega$

$\mathrm{Xr}=0.2268 \Omega$

$\mathrm{Xm}=9.0703 \Omega$

Nominal slip $=0.0355$

Two methods of voltage variation were employed to simulate the voltage unbalance as detailed in Case A and Case B below:

Case A: The line voltage $V_{a b}$ is allowed to increase above the nominal value, while $\mathrm{V}_{\mathrm{bc}}$ is reduced at about $60 \%$ of the rate at which $\mathrm{V}_{\mathrm{ab}}$ is increased. The magnitude of $\mathrm{V}_{\mathrm{ca}}$ is increased at about $20 \%$ of the rate at which $\mathrm{V}_{\mathrm{ab}}$ is increased. The result of the simulation is depicted by the graphs in figure 2 to figure 9

Case B: Line voltage $\mathrm{V}_{\mathrm{bc}}$ is reduced below the nominal value, while $\mathrm{V}_{\mathrm{ab}}$ is reduced at about $40 \%$ of the rate at which $\mathrm{V}_{\mathrm{bc}}$ is reduced. The magnitude of $\mathrm{V}_{c a}$ is increased at about $80 \%$ of the rate at which $\mathrm{V}_{\mathrm{bc}}$ is reduced. The result of the simulation is depicted by the graphs in figure 10 to figure 17

\section{Results and discussion}

The simulation for both case-A and case-B, which were started from a balanced voltage condition revealed vital details on the consequences of voltage unbalance on induction motor performance. The results are shown graphically by figure 2 to figure 17. For each graph, the instantaneous values are plotted as a percentage of the value for the balanced voltage operation. The values are compared at 5\% Unbalance Voltage (5\% UV) and $10 \%$ Unbalance Voltage ( $10 \% \mathrm{UV})$.

It is observed that when the rotor phase A winding loss is $121 \%$ at $5 \%$ UV and $205 \%$ at $10 \%$ UV for Case-A, for Case-B it is $95 \%$ at $5 \% \mathrm{UV}$ and $103 \%$ at $10 \% \mathrm{UV}$ respectively, whereas for the stator when the stator phase A loss is $121 \%$ at $5 \%$ UV and $203 \%$ at $10 \%$ UV for Case-A, for Case-B it is $116 \%$ at $5 \%$ UV and $181 \%$ at $10 \%$ UV respectively.

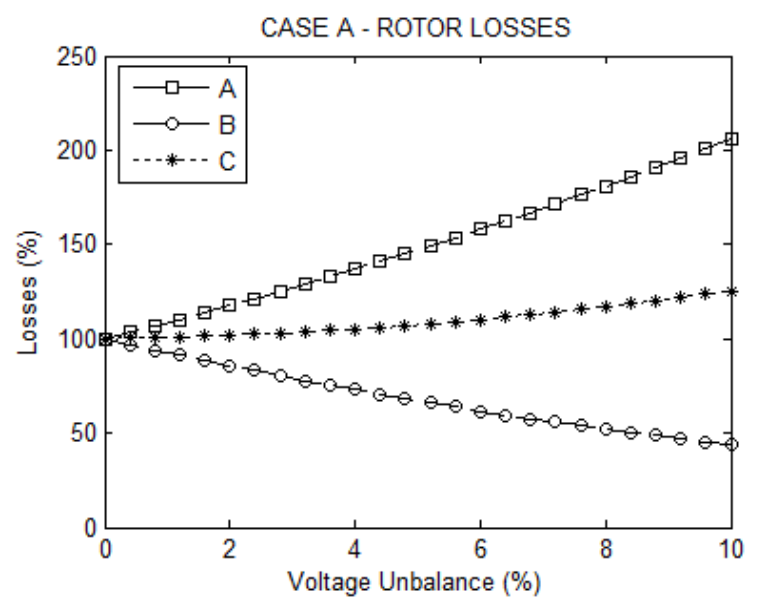

Fig 2. The losses in the motor rotor windings

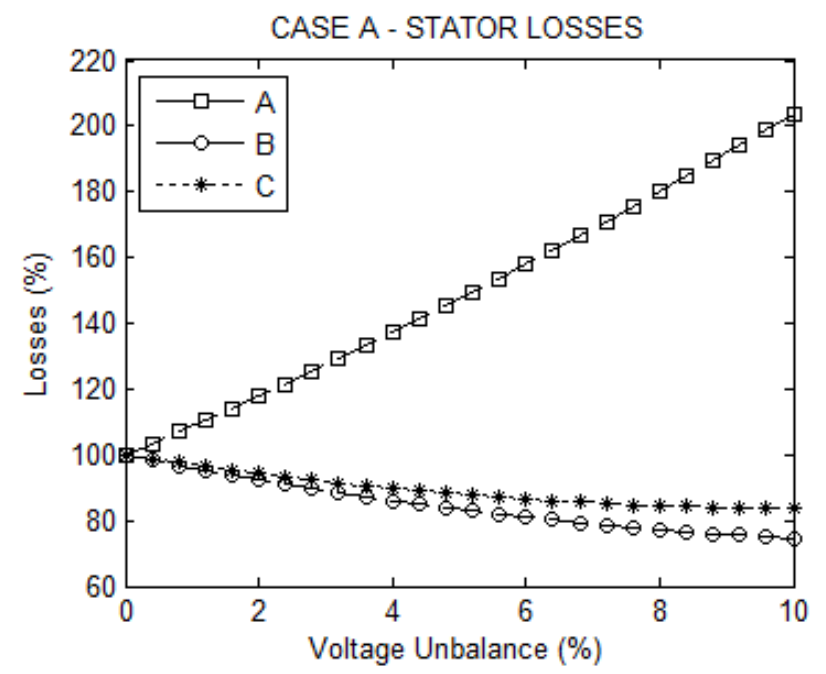

Fig 3. The losses in the motor stator windings

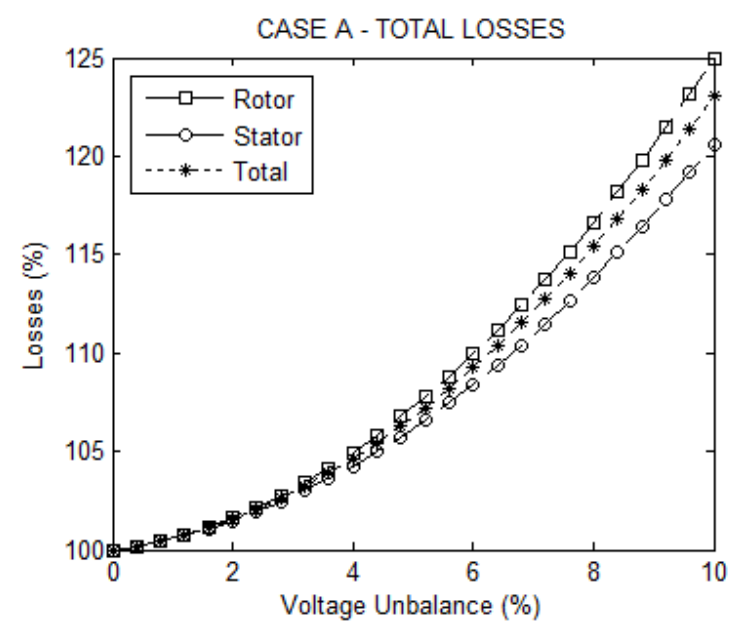

Fig 4. The total motor winding resistive losses 
Adekitan Aderibigbe, Ayodeji Ogunjuyigbe, Raphael Ayodele and Isaac Samuel/

Journal of Engineering Science and Technology Review 10 (5) (2017) 136-143

CASE A - VARIATION OF MAGNETISING CURRENT

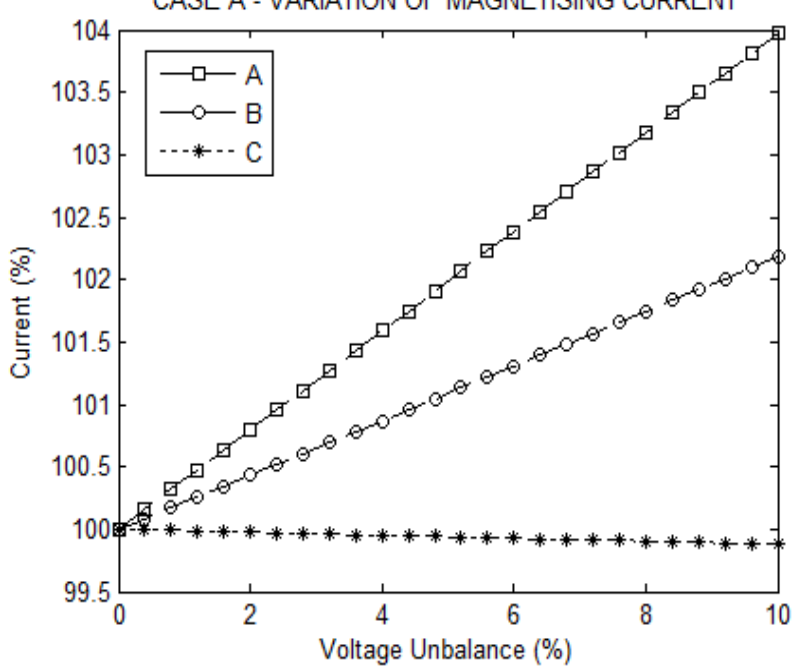

Fig 5. Magnetizing current variation with increase in unbalance

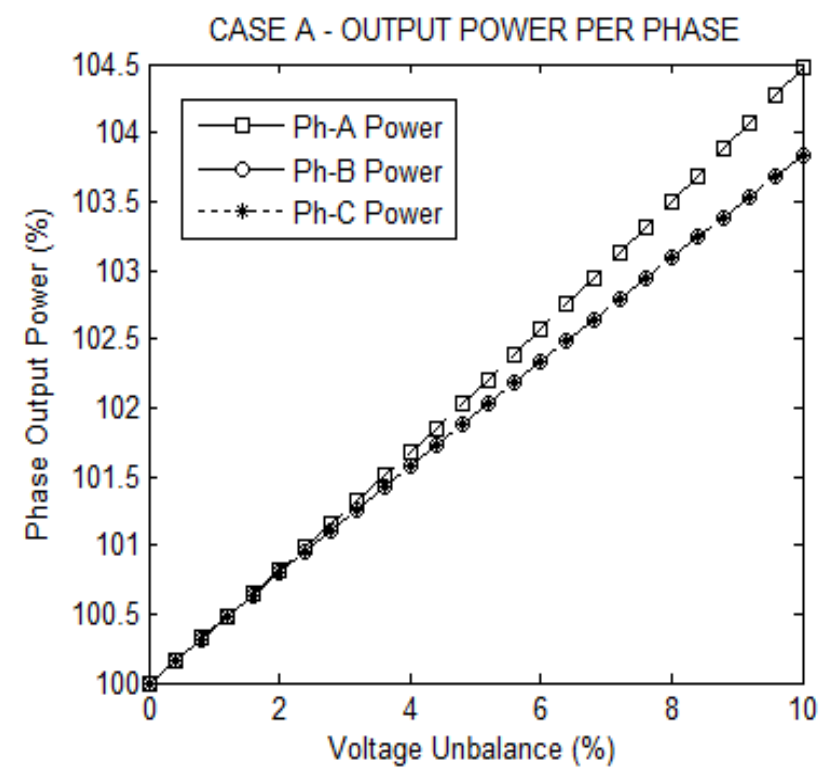

Fig 6. Motor output power per phase

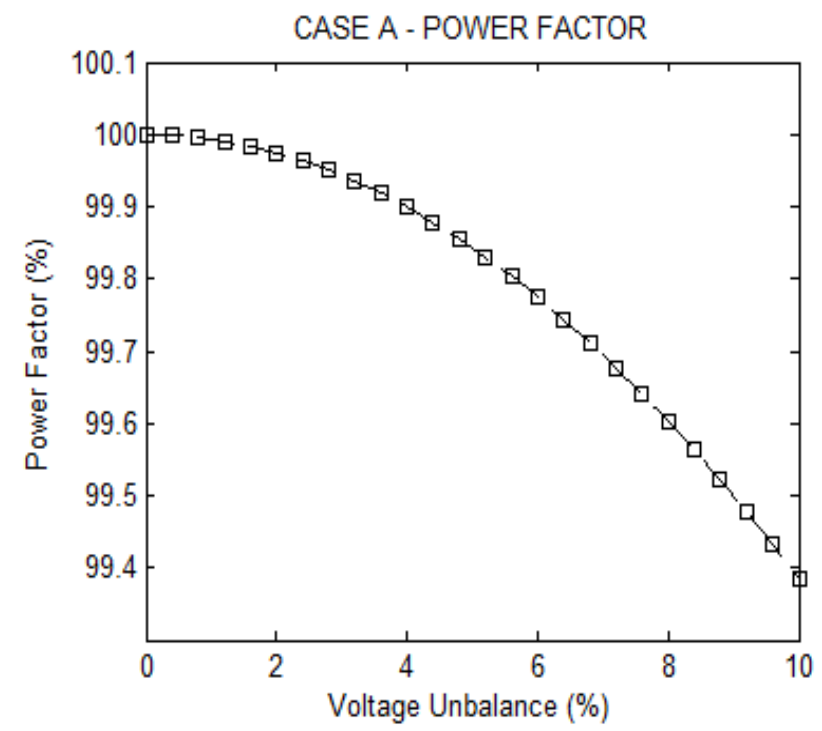

Fig 7: Power factor variation with voltage unbalance

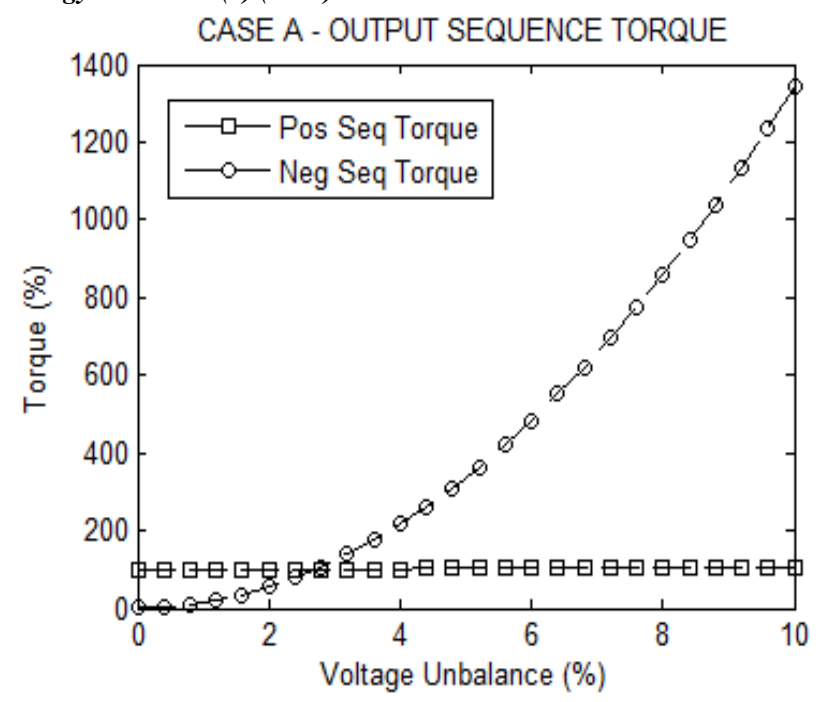

Fig 8. Positive \& negative sequence torque variation

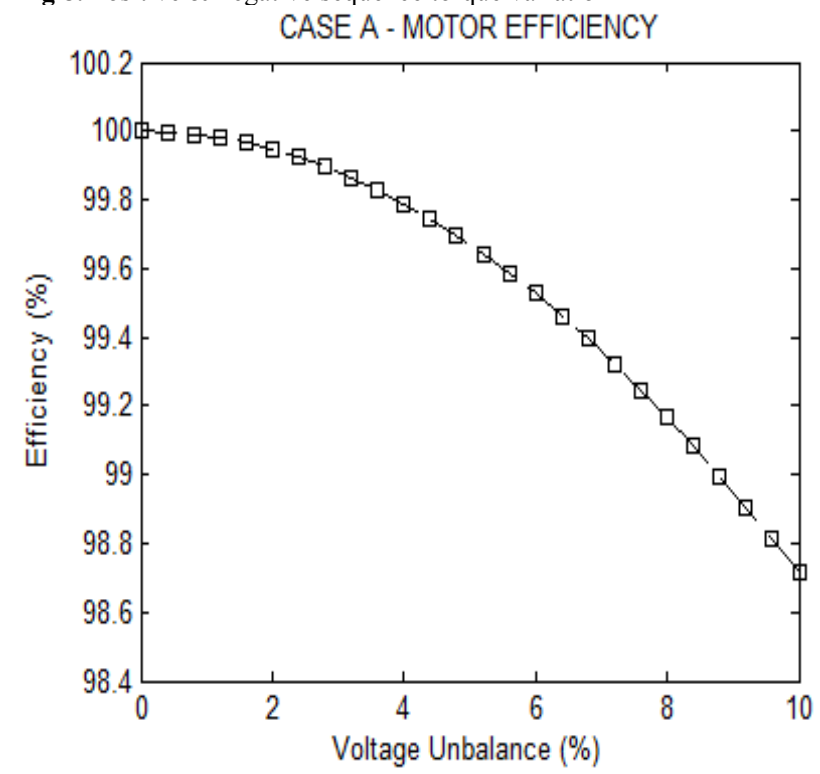

Fig 9. Reduction in Motor efficiency with increasing \% unbalance

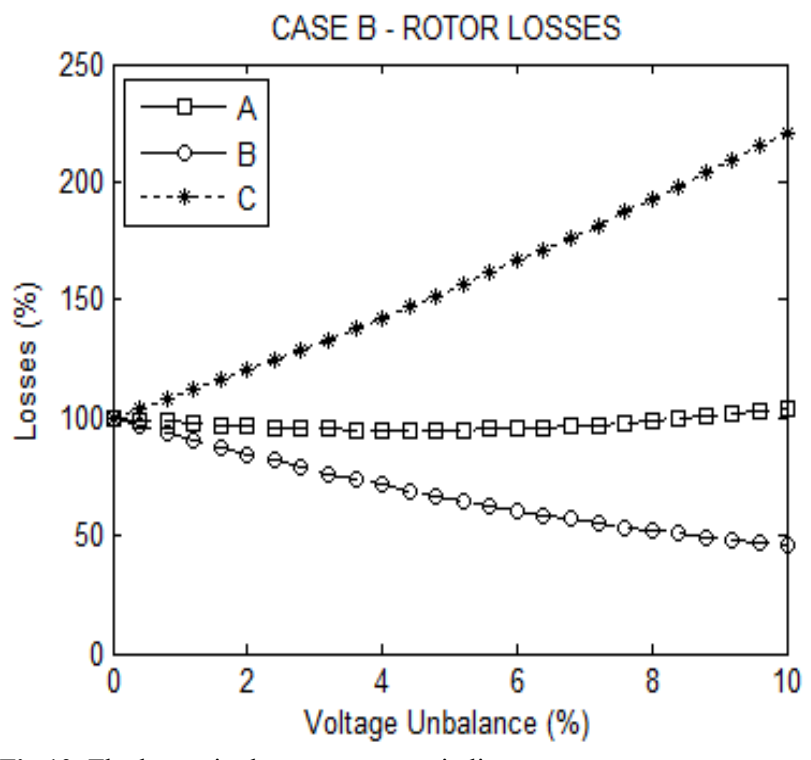

Fig 10. The losses in the motor rotor windings 
CASE B - STATOR LOSSES

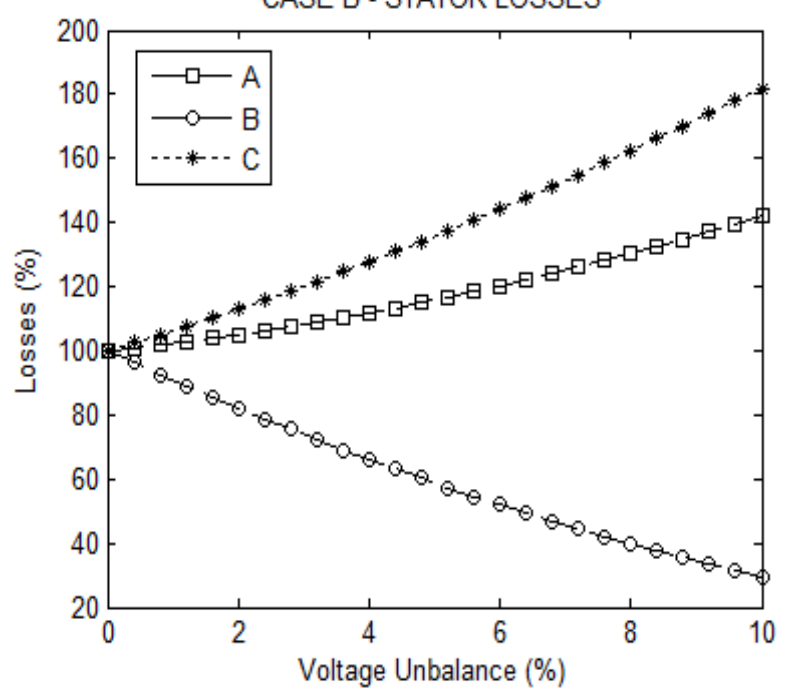

Fig 11. The losses in the motor stator windings

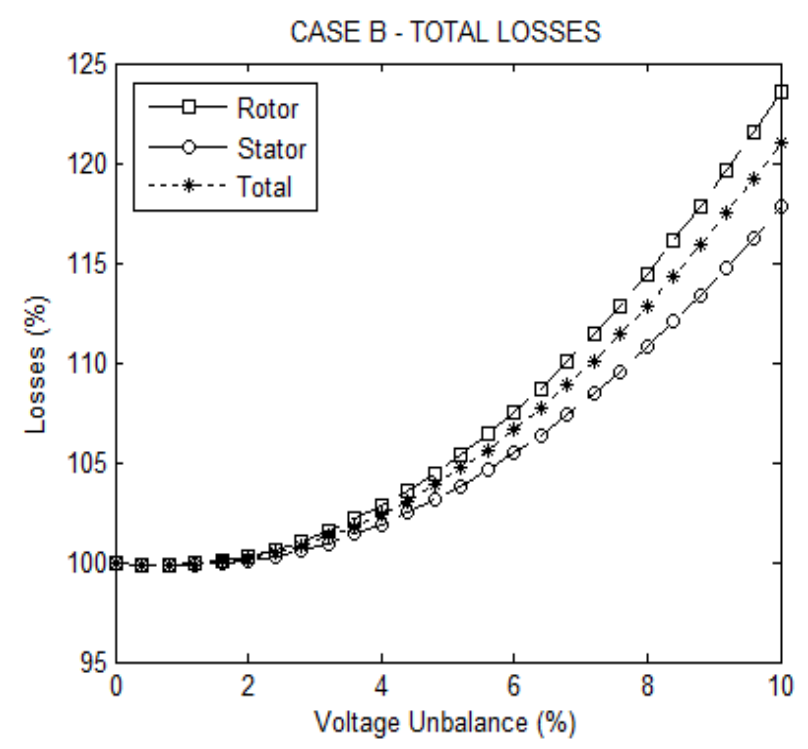

Fig 12. The total motor winding resistive losses

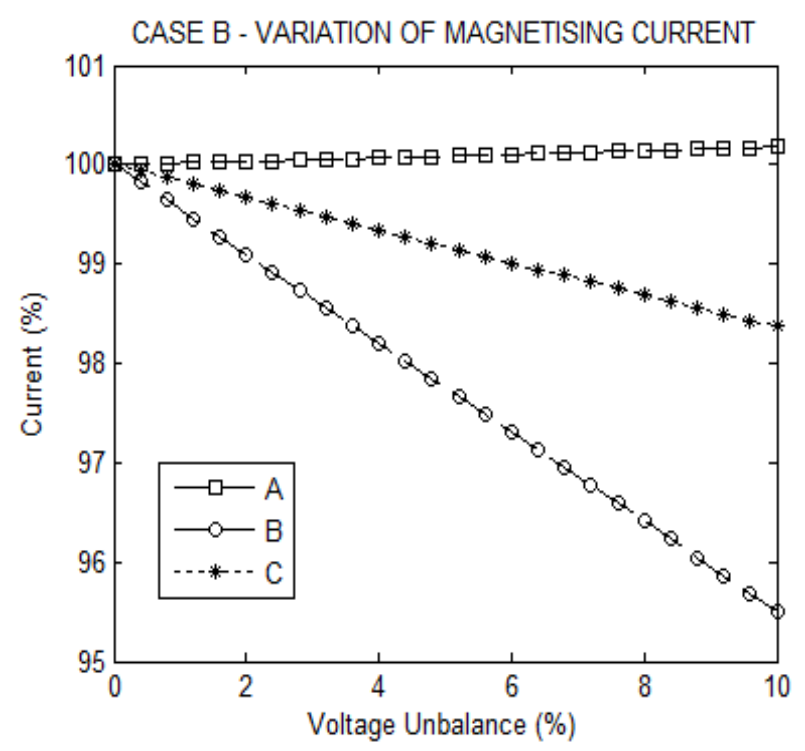

Fig 13. Magnetizing current variation with increase in unbalance

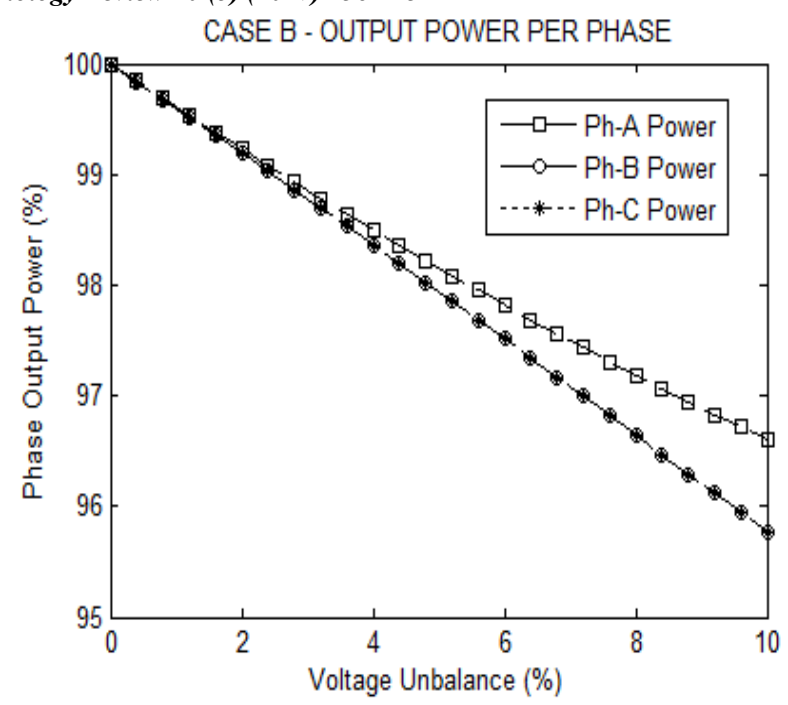

Fig 14. Motor output power per phase

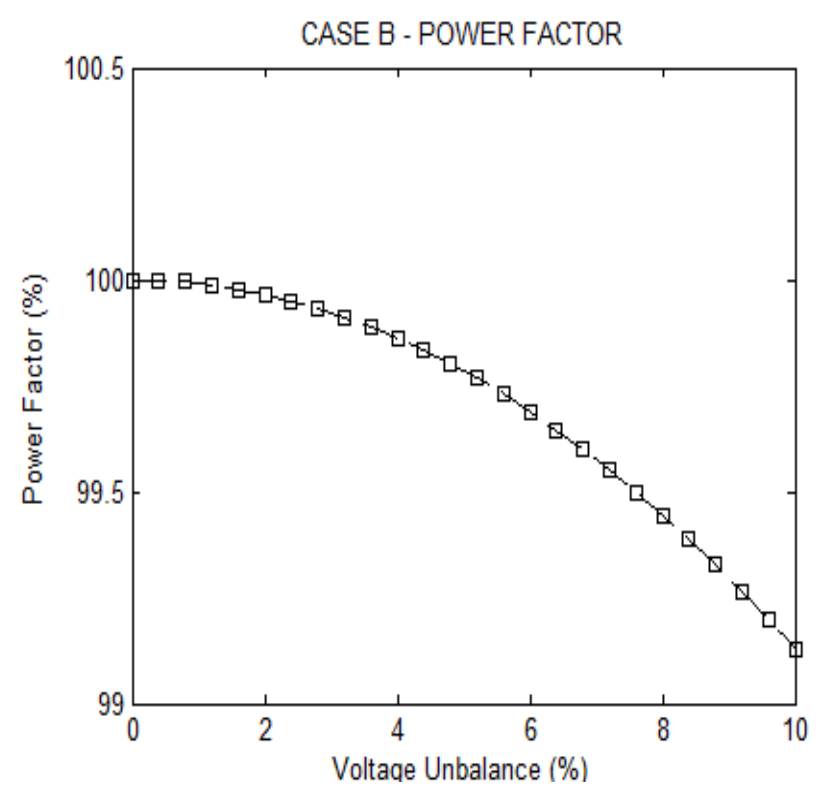

Fig 15. Power factor variation with voltage unbalance

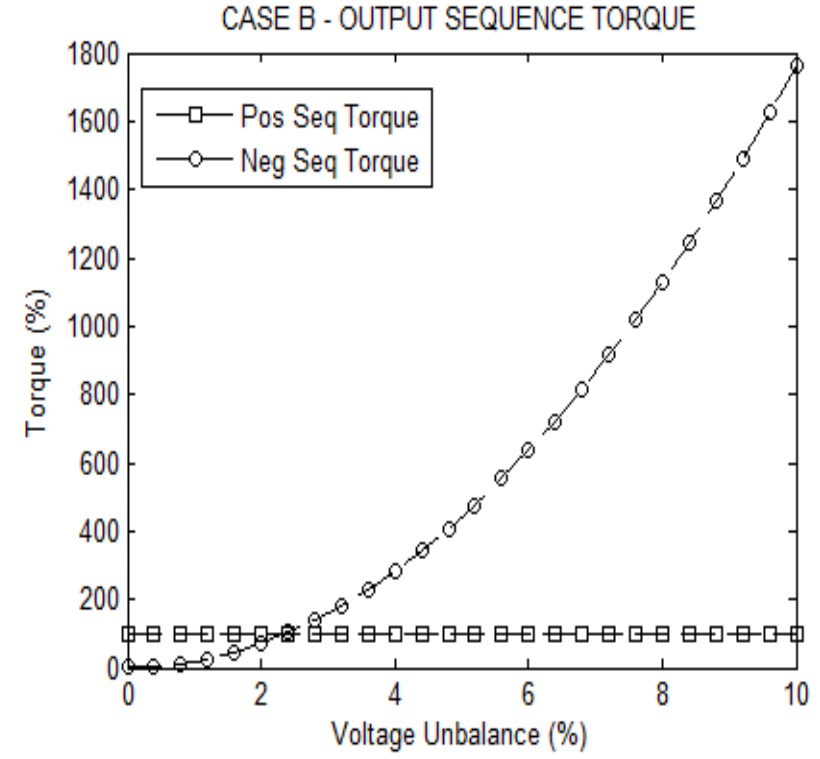

Fig 16. Positive \& negative sequence torque variation 
Adekitan Aderibigbe, Ayodeji Ogunjuyigbe, Raphael Ayodele and Isaac Samuel/

Journal of Engineering Science and Technology Review 10 (5) (2017) 136-143

CASE B - MOTOR EFFICIENCY

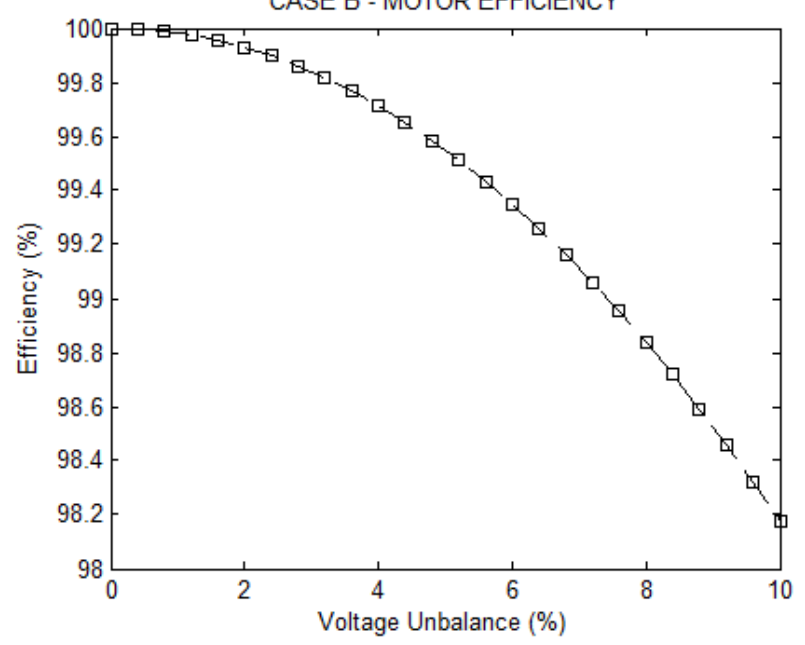

Fig 17. Reduction in Motor efficiency with increasing \% unbalance

The variation in the magnetizing current shows a maximum deviation of $4 \%$ at $10 \%$ UV from the balanced condition for phase $\mathrm{A}$, it is $101 \%$ at $5 \% \mathrm{UV}$ and $102 \%$ at $10 \% \mathrm{UV}$ for phase B. For case-B, the magnetizing current for phase A remained fairly constant, for phase B it dropped to $97 \%$ at $5 \% \mathrm{UV}$ and $95 \%$ at $10 \%$ UV while for phase C it dropped to $99 \%$ at $\% \%$ $\mathrm{UV}$ and $98 \%$ at $10 \mathrm{UV}$.

A very significant variation from the balanced state is observed for the negative sequence torque. The negative sequence torque which does no useful work varied as follows; for Case- $\mathrm{A}$ it is $333 \%$ at $5 \% \mathrm{UV}$ and $1342 \%$ at $10 \% \mathrm{UV}$, for Case-B it is $435 \%$ at $5 \%$ UV and $1761 \%$ at $10 \%$ UV. The positive and working component of the torque remained fairly constant and this validates the fact that voltage unbalance majorly affects the negative sequence component of a motor.

For Case-A as the percentage of voltage unbalance increased from $5 \%$ to $10 \%$, the total rotor loss changed by $116.82 \%$ while for Case-B it changed by $118.09 \%$. The total stator loss for Case-A changed by $115.23 \%$ while for Case-B it changed by $115.68 \%$. This implies that as a result of voltage unbalance a greater percentage increase in winding loss occurs in the rotor than in the stator.

The results show clearly that the way the voltage unbalance occurs in each phase determines the effect on the motor output and attributes. Hence to ensure voltage balance, due attention must be paid to all the phases of the supply. This study also revealed that the magnitude and manner of change of the effective average voltage is a determinant factor in motor performance under unbalanced supply conditions. For case-A that experienced an increase in average voltage, the negative sequence component was not as high as that of case-B that experienced a reduction in effective average voltage.

As negative sequence current and components increases, the total losses in a three phase induction motor increases with increasing voltage unbalance, which leads to excessive increase in motor temperature, wastage of energy and higher tendency for insulation failure. This reduces motor efficiency and increases energy cost [15].

It is significant to note that above the NEMA recommended $0-5 \%$ voltage unbalance tolerance limit, the negative sequence current and associated losses increased at a higher rate, which affirms the need to always ensure that the tolerance limit is not exceeded.

\section{Conclusion}

This paper has established the menace of unbalance voltage conditions on the performance of three phase induction motors. Voltage unbalance leads to the generation of unusable negative sequence currents and torque which wastes energy and weakens insulation, and these negative effects even becomes greater as percentage unbalance exceeds the NEMA recommended 5\% allowance limit. Voltage unbalance is an undesirable operational condition that should be proactively monitored and mitigated using appropriate methods such as motor de-rating, line load inspection, and line voltage unbalance detection devices. Globally, a reduction in energy wastage as a result of voltage unbalance related issues particularly in industries will help save several millions of dollars spent yearly on unproductive energy dissipated mostly as heat. This is a good culture that will result in expedient energy conservation and increase in operational efficiency and effectiveness.

Access article distributed under the terms of the Creative Commons Attribution License

\section{References}

1. Gosbell, V.J., Technical Note No. 6 - VOLTAGE UNBALANCE. 2002, Integral Energy Power Quality Centre, School of Electrical, Computer \& Telecommunications Engineering, University of Wollongong.

2. Quispe, E., G. Gonzalez, and J. Aguado, Influence of Unbalanced and Waveform Voltage on the Performance Characteristics of Three-phase Induction Motors, in In International Conference on Renewable Energy and Power Quality. 2004: Barcelona.

3. Kersting, W.H. and W.H. Phillips, Phase Frame Analysis of the Effects of Voltage Unbalance on Induction Machines. IEEE Transactions on Industry Applications, 1997. 32(2): p. pp.415-20.

4. Pillay, P. and M. Manyage, Definitions of voltage unbalance. IEEE Power Engineering Review, 2001. 21(5): p. 50-51.

5. Annette, V.J., Voltage unbalance: Power quality issues, related standards and mitigation techniques. 2000, Electric Power Research Institute: EPRI, Palo Alto, CA. p. 40.

6. Wallace, A.K.e., The measured effects of under-voltage, overvoltage and unbalanced voltage on the efficiency and power factor of induction motors over wide ranges of load, in Electrical Machines and Drives, 1997 Eighth International Conference on (Conf. Publ. No. 444). 1997, IET Cambridge. p. 258 - 262.

7. Kersting, W.H. Causes and Effects of Unbalanced Voltages Serving an Induction Motor. in In Rural Electric Power Conference 2000. Louisville, KY: IEEE.
8. Raj, C.T., P. Agarwal, and S.P. Srivastava. Performance Analysis of a Three-Phase Squirrel-Cage Induction Motor under Unbalanced Sinusoidal and Balanced Non-Sinusoidal Supply Voltages. in In International Conference on Power Electronics, Drives and Energy Systems PEDES '06. 2006. New Delhi: IEEE.

9. Lee, C.-Y., et al., Effects of Various Unbalanced Voltages on the Operation Performance of an Induction Motor under the Same Voltage Unbalance Factor Condition, in In Industrial and Commercial Power Systems Technical Conference, 1997 Annual Meeting. 1997, IEEE: Philadelphia, PA,.

10. KANWARJIT, S.S. and C. VINEET. Simulations of Three- Phase Induction Motor Operating with Voltage Unbalance. in In Proceedings of the 8th WSEAS International Conference on ELECTRIC POWER SYSTEMS, HIGH VOLTAGES, ELECTRIC MACHINES. 2008. Venice, Italy: WSEAS Press.

11. Quispe, E., P. Vigeo, and J. Cogollos, Statistical equations to evaluate the effects of voltage unbalance on the efficiency and power factor of a three-phase induction motors. WSEAS Transactions On Circuits And Systems, Brasil, 2005. 4(4): p. 234 239.

12. Abhishek, C., T. Padmanabh, and R. Dogga, Assessment of induction motor performance under supply voltage unbalance: $A$ review. In Engineering and Systems (SCES), in Engineering and 
Adekitan Aderibigbe, Ayodeji Ogunjuyigbe, Raphael Ayodele and Isaac Samuel/

Journal of Engineering Science and Technology Review 10 (5) (2017) 136-143

Systems (SCES), 2013 Students Conference. 2013, IEEE: Allahabad.

13. Faiz, J., E. H., and P. Pillay, Influence of Unbalanced Voltage on the Steady-State Performance of a Three-Phase Squirrel-Cage Induction Motor. IEEE TRANSACTIONS ON ENERGY CONVERSION, 2004. 19(4): p. pp.657-62.
14. Giridhar, K.P., B.R. C., and R.S. Aithal, The South Pacific Journal of Natural Science. Impact of voltage unbalance on the performance of three-phase induction motor, 2006. 24(1): p. pp.4550.

15. Annette, J.V. and B.B. Basudeb, Assessment of Voltage Unbalance. IEEE transactions on power Delivery, 2001. 16(4). 